\title{
Os taxistas de Florianópolis/SC e o ambiente noturno urbano da cidade*
}

\author{
Gabriel Luis Rosa \\ Universidade Federal de Santa Catarina
}

Esta pesquisa se propõe a analisar o universo dos taxistas em serviço durante a madrugada em Florianópolis, horário este em que grande parte da população não se locomove e o espaço se transforma. O trabalho foi feito a partir da observação participante e do uso de técnicas de pesquisa qualitativa, e devido ao caráter breve da análise, optou-se por pelo campo em um único ponto de táxi "chave" na cidade, localizado na Praça Santos Dumont e próximo à Universidade Federal de Santa Catarina. São abordados tópicos como a relação de tal grupo com o trânsito, com os clientes e com fatores específicos como a criminalidade e o rendimento diferenciado.

Palavras-chave: Taxistas - Florianópolis/ $\mathrm{SC}$ - Antropologia urbana - Espaço urbano - Campo noturno
This paper analyzes the sociability of taxi drivers with night shifts in Florianopolis/SC (Brazil). We discuss topics such as the relationship of the group with the traffic jams, the customers and factors such as high crime danger and the distinguished income. The paper was made based on the participant observation and the use of qualitative research techniques. Due to the brief character of this essay, we chose to focus the field on single important tax stand in the city, located in the Praça Santos Dumont, near the Federal University of Santa Catarina.

Keywords: Tax drivers - Florianópolis/SC - Urban anthropology - Urban space Night field

\section{Introdução}

Teste trabalho, é feita uma breve pesquisa etnográfica com o grupo de 1 taxistas em serviço durante a madrugada de Florianópolis (principalmente da 0 h às $4 \mathrm{~h}$, aproximadamente), no ponto de táxi localizado nas imediações da Praça Santos Dumont ${ }^{2}$ e próximo à Universidade Federal de Santa Catarina (UFSC). O ponto é o mais movimentado da região por ser também circundado por uma praça, prédios de lojas, um supermercado e inúmeras moradias de alunos, como pequenos apartamentos e quitinetes.

\footnotetext{
* The relationship Florianopolis taxi drivers with the city's night context

${ }^{1}$ Programa de Pós-Graduação em Antropologia, CFH/UFSC. Endereço para correspondências: Rua Europa, 106, Apto. 424, Trindade, Florianópolis, SC, 88036-135 (gabriel.luisrosa@gmail.com).

${ }^{2}$ Localização do ponto de táxi no mapa: <http://tinyurl.com/8w6dyqf $>$.
} 
Foram utilizadas técnicas específicas da Antropologia urbana, como entrevistas qualitativas $^{3}$ em associação com a observação participante, além de uma série de conversas informais sobre assuntos relevantes para os indivíduos que exercem tal função. As visitas ao campo foram realizadas entre maio de 2011.

Primeiramente, é importante ressaltar como a teoria antropológica, há muito, não enxerga mais os inúmeros segmentos de uma sociedade como isolados e desconexos entre si. Desta maneira, a pergunta (re)feita por José Cantor Magnami (2002) e que acaba norteando esta pesquisa é um antigo dilema tanto da Sociologia quanto da Antropologia urbana: "qual seria, na estratégia proposta, a unidade de análise? A cidade em seu conjunto ou cada prática cultural em particular? Ou, nos termos de uma dicotomia mais conhecida, trata-se de antropologia $d a$ cidade ou na cidade?". Para então compreender melhor a rede de relações que o grupo possui com o ambiente noturno de Florianópolis, foi também realizada uma pesquisa bibliográfica de ordem metodológica sobre o campo etnográfico noturno, o qual será melhor definido a seguir.

A pesquisa etnográfica realizada em centros urbanos tem especificidades que a diferencia de outros espaços de pesquisa do antropólogo. Primeiramente, a própria questão da proximidade com o espaço de pesquisa pode ser, ao mesmo tempo, conveniente e perigosa; afinal, a aproximação prévia entre pesquisador e nativo pode tanto facilitar a relação entre eles quanto dificultar a possibilidade de um distanciamento por parte do etnógrafo, que não percebe uma série de elementos que the também parecem "naturais". Assim, como pondera Paul Ricoeur (1977) sobre o dilema etnográfico objetividade x proximidade: "ou praticamos a atitude metodológica, mas perdemos a densidade ontológica da realidade estudada, ou então praticamos a atitude de verdade, e somos forçados a renunciar à objetividade das ciências humanas".

A proximidade do ponto de táxi com a Universidade faz dele um ponto de passagem a uma parte considerável da comunidade acadêmica $\mathrm{O}$ contato diário com uma região pode causar a ilusão, a princípio, de se estar a meio caminho andado para compreender melhor a problemática em questão.

Entretanto, como nos explica Gilberto Velho (1978; p. 39), "o que sempre vemos e encontramos pode ser familiar mas não é necessariamente conhecido, e o que não vemos e encontramos pode ser exótico mas, até certo ponto, conhecido". Acho importante tornar clara essa distinção entre familiar e conhecido, pois percebo como o ponto de táxi em questão se tornou, para mim, parte da "paisagem" da região (VELHO, 1978): algo que, de tão frequente no meu olhar, parou de chamar a minha atenção.

\footnotetext{
${ }^{3}$ Foram realizadas, no total, sete entrevistas "formais" com taxistas. O questionário, de caráter qualitativo, incluía apenas seis perguntas, mas que permitiam bastante flexibilidade por parte dos entrevistados, como "Quais as diferenças entre dirigir à noite ou durante o dia?", ou "Como você avalia a segurança do taxista em serviço durante a madrugada?". O resto das informações foi obtida em conversas informais ao longo do trabalho de campo.
} 
O exercício a que me propus foi, então, justamente o proposto por Roberto DaMatta (1981; p. 160): "é preciso transformar o familiar no exótico". Tal dificuldade levou, por exemplo, Eduardo Campos Rocha (2004; p. 2) a levar a observação participante ao "extremo" e alugar um táxi para estreitar a sua relação com os trabalhadores, mas esforçando-se ao mesmo tempo para "não passar da condição de um observador participante para a de participador observante".

Acredito ser crucial, para a tarefa a qual me comprometi, descrever o ambiente em que a pesquisa foi realizada, principalmente durante a noite. A praça Santos Dumont concentra, na madrugada, uma população bem específica: se, durante o dia e até o começo da madrugada, o bar da Praça está aberto e o movimento é relativamente grande, a partir de aproximadamente meianoite (quando fecham também os carrinhos de cachorro-quente e o serviço de ônibus pára de funcionar) ele se torna um local considerado "perigoso" por todos os taxistas entrevistados. Entretanto - pelo menos no tempo em que esta pesquisa foi realizada - não houve nenhum tipo de problema relacionado à criminalidade no ponto da Praça. "Essa bagunça incomoda um pouco, né? Barulho, sujeira. Mas nunca tive nenhum problema sério com isso por aqui", me relatou o taxista Rafael, trabalhando no ponto há cerca de um ano.

De fato, como explica Marcos Góis (2010), o grande diferencial entre os dois períodos do dia está no fato de que a paisagem urbana pode mudar entre eles sem necessariamente perder a sua constituição física - na prática, apesar do espaço físico permanecer intacto, a forma que as relações sociais acontecem fora do horário de funcionamento do comércio e da circulação massiva de habitantes acaba sendo completamente diferente. Partindo de tal pressuposto, torna-se possível entender como, mais do que durante o dia, as ações do indivíduo durante a noite se guiam em grande parte pela distinção entre espaços iluminados/movimentados ou não:

Dessa forma, um mesmo lugar pode possuir durante o dia certo arranjo de objetos, um ritmo de circulação de pessoas, a presença de determinados grupos predominantes. À noite, este mesmo espaço, com o mesmo arranjo de objetos pode, entretanto, ser preenchido por outra vida social. O ritmo e os comportamentos podem mudar assim como a forma de apropriação do espaço. Algumas ruas que durante o dia possuíam movimentação intensa tornam-se locais pouco frequentados, perigosos e até mesmo sombrios (GÓIS, 2010; p. 43). 


\section{HUMANAS}

Já à primeira vista, o medo da criminalidade parece ser um fator muito presente na vida de uma pessoa que trabalha nas ruas da cidade de madrugada. Como a territorialidade se transforma, e consequentemente a maneira como as pessoas interagem com o lugar também, a noite acaba se tornando um lugar de alta estigmatização - imagens que geralmente incluem violência, assaltos e "vagabundagem" (PERLONGHER, 2005).

Tal como pode ser observado com as linhas de ônibus que circulam durante a noite, a movimentação escassa também pode abrir espaço para assaltos e violência, mesmo que os trabalhadores tomem medidas específicas, como não apanhar passageiros na rua ou que não tenham ligado para a Central Rádio-Táxi de Florianópolis. Entretanto, para Janice Caiafa (2002), que estuda os motoristas e cobradores de ônibus no Rio de Janeiro, a criminalidade é um medo constante na vida de grande parte dos funcionários do transporte em todos os momentos do dia. Desta maneira, é interessante refletir sobre o medo de quem trabalha à noite como, talvez, um reflexo desta estigmatização da noite.

O medo de assaltos levou, por exemplo, o Sindicato dos Taxistas da Grande Florianópolis a permitir que os motoristas se recusem a transportar passageiros a partir das $18 \mathrm{~h}$ - principalmente para locais considerados "perigosos" pelos mesmos, como morros, comunidades carentes ou locais mais afastados do centro urbanizado. Apanhar clientes na rua durante a noite "apenas se for um cara bem apessoado, se tiver uma criança, uma família", me explica o taxista Rafael. No dia em que conversei com o mesmo, até as $23 \mathrm{~h}$ já haviam ocorrido duas tentativas de assalto na cidade, fracassadas graças ao sistema de comunicação entre os motoristas, que possuem códigos específicos para alertar pelo rádio que estão em perigo para os colegas (como, por exemplo, "não posso fazer uma corrida agora, estou com o cabo de freio com problemas" ou algo parecido que, previamente combinado, funcionada como um pedido de ajuda). Assim que alertados, os outros taxistas que se encontram na região vão até o local indicado e organizam um "comboio" para coagir o assaltante.

Tal sentimento de medo pode ser percebido em pesquisas semelhantes a esta. Observemos o discurso registrado por Veloso, Filho, Medeiros e Araújo (2009) sobre o trabalho do taxista e a criminalidade em João Pessoa, Paraíba:

\footnotetext{
É [uma profissão] arriscada, né? Arriscada porque o taxista é muito visado pelos ladrões, apesar da... da... do dinheiro que a gente apura por dia, é... é, fica muito visado o... o... qualquer pessoa, você sabe que qualquer pessoa entra no táxi e a gente não sabe quem entra.
}

Para compreender melhor as formas de narrativas dos taxistas e a relação destes com o medo e a criminalidade, recomenda-se a pesquisa de Soares 
e Silveira (2008) em Belém do Pará. Para os autores, "há sempre a representação do passado como uma época em que a violência não existia, o que contrasta nitidamente com o cotidiano atual dos taxistas, no qual o risco de assaltos e de assassinatos parece ser mais palpável, constituindo assim, o objeto de preocupação primordial". Assim, fica claro que tal tipo de temor reflete a superexposição do trabalhador que exerce sua função em períodos noturnos, "em especial pelos taxistas e outros profissionais que possuem o espaço público como locus de trabalho por excelência" (SOARES \& SILVEIRA, 2008; p. 92).

\section{A rotina do taxista na madrugada}

O motorista de táxi em Florianópolis realiza turnos de 24h seguidas, iniciando às $6 \mathrm{~h}$ da manhã e descansando sempre que possível nos pontos em horários menos movimentados. Cada veículo tem licença para apanhar passageiros em quaisquer lugares enquanto estiver em movimento, mas deve seguir um regimento que divide os pontos da seguinte maneira: com exceção dos registrados para o Aeroporto e para a Rodoviária, qualquer taxista pode também aguardar em pontos que não o "seu", desde que "ceda o cliente" para aqueles que estiverem registrados no local. Apenas um veículo de outra localidade pode permanecer em cada ponto, podendo os licenciados inclusive ligar para a Central de Táxi para denunciá-los. O taxista denunciado leva uma suspensão de duas horas e, em caso de reincidência, de um dia inteiro.

Graças ao sistema de rodízio de 24 horas, cada taxista cobre todos os períodos do dia. Assim, esta pesquisa - que inicialmente se propôs a trabalhar com o ambiente noturno de Florianópolis - pode ser associada, com as devidas adaptações, a todo o serviço de táxi da cidade. Entretanto, optou-se pela realização do trabalho de campo apenas em horários noturnos, permitindo assim também uma reflexão sobre ambiente noturno em associação com as falas do grupo.

O cotidiano de um taxista durante a noite é marcado por elementos que alteram a sua rotina e sua movimentação dentro do espaço urbano. A "vida noturna" pode causar inclusive implicações no funcionamento biológico dessas pessoas (ROTENBERG, 2001), o que torna a pesquisa com os agentes deste serviço ainda mais peculiar. Entretanto, devido à brevidade do estudo, tais alterações também não serão explicitadas com profundidade, mantendo-se então o foco apenas na relação do taxista com o espaço urbano noturno de Florianópolis.

O trabalho durante a noite de um taxista se justifica pela demanda do serviço - principalmente em horários onde o transporte coletivo de Florianópolis não está em funcionamento ${ }^{4}$. As casas noturnas e pontos específicos de interação social,

\footnotetext{
${ }^{4} \mathrm{O}$ sistema de transporte público de Florianópolis funciona das 5 da manhã à meia-noite, além das linhas do "Madrugadão", que fazem alguns trajetos diferenciados e possuem um horário específico - geralmente, de hora em hora.
} 
como bares, "alguns só acessíveis através do táxi - que representavam, durante a noite, fonte de sustento para o taxista" (SOARES \& SILVEIRA, 2008) costumam influenciar a rotina de trabalho do grupo. Assim, de maneira geral, os elementos que prejudicam o trabalho noturno (como o medo e o estresse) são compensados apenas pela remuneração maior, partindo do pressuposto que a disponibilidade de ônibus durante tal horário é reduzida, fazendo com que muitos indivíduos prefiram a facilidade do transporte de táxi.

\begin{abstract}
Mais que um simples aumento no valor da tarifa, $o$ tempo da Bandeira 2 representa a derradeira oportunidade para o taxista apurar o dinheiro necessário para completar sua diária, ou a quantia que julgue suficiente... Seus companheiros do dia podem não ser os mesmos da noite. E normalmente não o são. Os espaços da cidade se reconfiguram e novos personagens compõem o cenário urbano. Nesse espaço, não há lugar para o descuido. A morte ronda o trabalho. O que pode representar a "salvação financeira", a "grande corrida", pode ser a derradeira da vida. Não há por quem chamar (ROCHA, 2004; p. 11-12).
\end{abstract}

Um dos motoristas com quem conversei - Marcelo, taxista há quatro anos - não estava licenciado para trabalhar na Praça Santos Dumont, mas costumava passar pelo local em horários de movimento da Universidade. O mesmo me explicou que o trabalho à noite compensa apenas pelo rendimento diferenciado; rodando com bandeira $2^{5}$, o valor arrecadado pelo trabalhador acaba sendo a principal justificativa para o trabalho durante a madrugada. Segundo mais de um informante, a renda líquida de um taxista em Florianópolis varia, em média, entre $\mathrm{R} \$ 1$ mil e $\mathrm{R} \$ 1.300$.

Mesmo sendo o período noturno um dos mais lucrativos (junto com os horários de pico, como meio-dia ou 18h), tal função é vista pelos taxistas como "extremamente cansativa". O estresse, de fato, parece ser um dos elementos mais evidentes na vida do motorista de táxi. Como explica Dornelas (2006; p. 23), "Os inúmeros sustos sofridos no trânsito diariamente nas doze, quatorze e até dezesseis horas por dia, podem contribuir para o estresse destes trabalhadores". O autor também define a criminalidade como um fator de tensão constante para o trabalhador, como pôde ser observado também em Florianópolis.

\footnotetext{
${ }^{5}$ Bandeirada: $\mathrm{R} \$ 3,40$ (centro), $\mathrm{R} \$ 5,10$ (aeroporto). Bandeira 1: $\mathrm{R} \$ 1,81$ (centro), $\mathrm{R} \$ 2,02$ (aeroporto). Bandeira 2: R \$ 2,16 (centro)/ R \$2,42 (aeroporto). Hora parada: $\mathrm{R} \$ 9,10$ (centro)/ R\$ 9,81 (aeroporto).
} 
As doenças relacionadas ao estresse também se tornam mais presentes em rotinas exaustivas como a destes trabalhadores. Em pesquisa com taxistas no Rio de Janeiro, por exemplo, Vieira (2009) constata que existe uma clara relação entre a hipertensão arterial e o serviço de taxista, enfermidade esta causada pela sobrecarga de trabalho da categoria e pelo grande número de dias de trabalho por semana e pela carga horária diária. Em relação aos taxistas da Praça Santos Dumont, apenas um me declarou "sentir-se" seriamente com problemas de saúde, como falta de ar, dores no corpo ou até mesmo estresse.

As viagens realizadas durante a noite representam também outro dilema para os taxistas: se, por um lado, o tráfego reduzido facilita a locomoção e reduz o nervosismo causado pelo convívio com os engarrafamentos, por outro lado existe o perigo de, por exemplo, dormir no volante (risco este ainda mais elevado partindo do fato de que, durante a madrugada, o taxista já está há quase completando $24 \mathrm{~h}$ seguidas em serviço).

Em muitas ocasiões, por ser a condução de veículos uma atividade de prática habitual diária, se perde a consciência de que ela é um processo complexo, no qual se tomam decisões com grave perigo para a vida, de uma maneira rápida, num meio constantemente mutante, inundado de uma enorme estimulação ambiental. Isso exige que toda nossa capacidade psicofísica esteja em perfeito estado quando realizamos a atividade de conduzir (HOFFMANN \& LEGAL, 2003; p. 345).

Michel, um dos taxistas entrevistados, esteve envolvido em um acidente de trânsito no início do ano. Explicou-me ser o responsável pelo acidente após um momento de "vacilo": cortou a frente de outro veículo em um cruzamento, causando uma colisão leve. Contou-me também que, em momentos de cansaço, percebe estar menos atento e mais sujeito a acidentes no trânsito. "Tem que prestar mais atenção, porque o movimento fraco na rua causa a impressão de que acidentes acontecem apenas durante o dia. Na verdade, dirigir à noite acaba sendo tão perigoso quanto às $18 \mathrm{~h}$ - se você não ficar ligado".

\section{Conclusões}

A pesquisa etnográfica em ambientes urbanos propõe, ao mesmo tempo, uma negação de alguns dos métodos clássicos da disciplina - em seu nascimento, voltada para o estudo de sociedades "primitivas" - e a readaptação de outros. 
Como explica Gilberto Velho (1978), a Antropologia urbana ainda não está bem desenvolvida dentro das Ciências Humanas e está apenas se situando no campo do conhecimento antropológico, abrindo espaço para a experimentação de diferentes temas e métodos. Desta maneira, as dificuldades de se estudar uma sociedade "complexa" já se iniciam na tentativa de elaborar um recorte específico dentro de tais populações intimamente relacionadas - onde cada indivíduo inserido em algum grupo apresenta uma série de características próprias e participa de vários outros grupos, cabendo ao pesquisador encontrar as semelhanças (muitas vezes, extremamente sutis) entre os "nativos".

Se o trânsito faz parte da paisagem de uma cidade urbanizada como Florianópolis, podemos considerar o serviço de táxi como um importante objeto de análise para auxiliar na compreensão também do espaço noturno. A redução do tráfego em tais horários facilita a movimentação dos taxistas, que acabam se tornando muito mais procurados em horários de pouca circulação do transporte público municipal. Entretanto, a partir do discurso do próprio taxista, é possível perceber uma espécie de sacrifício pessoal por parte do trabalhador - ou seja, mesmo com o medo da criminalidade e com os fatores que agravam seus problemas de saúde, a melhor remuneração torna-se praticamente a única justificativa para tal preferência.

Compreender como os diversos grupos sociais interagem, mesmo que indiretamente, dentro de um espaço urbano noturno é uma tarefa que só pode ser realizada a partir de pelo menos uma breve compreensão de cada um deles. Assim, para entender os motivos que levam o taxista a trabalhar em horários alternativos, por exemplo, é preciso primeiramente saber como eles se relacionam com o trânsito, com a criminalidade, com os clientes ou com os outros taxistas, enxergando a realidade deles como parte de uma série de outros contextos intimamente conectados.

\section{Referências bibliográficas}

CAIAFA, J. Jornadas urbanas: exclusão, trabalho e subjetividade nas viagens de ônibus na cidade do Rio de Janeiro. Rio de Janeiro: Editora FGV, 2002.

DAMATTA, R. Trabalho de campo. In: Relativizando: uma introdução à Antropologia Social. Petrópolis: Vozes, 1981.

DORNELAS, R.A. Trabalhador taxista: Algumas considerações sobre sua saúde e seu processo de trabalho. Monografia apresentada à Escola Politécnica de Saúde Joaquim Venâncio, 2006. 
GÓIS, M.P.F. de. Cenários noturnos: sobre a espacialidade e os significados da iluminação urbana na cidade do Rio de Janeiro. Revista de Geografia, 27(2), Maio-Agosto, 2010.

HOFFMANN, M.H. \& LEGAL, E.J. Sonolência, estresse, depressão e acidentes de trânsito. In: M.H. HOFFMANN, R.M. CRUZ \& J.C. ALCHIERI (Orgs.). Comportamento humano no trânsito. São Paulo: Casa do Psicólogo, 2003.

MAGNAMI, J.C.G. De perto e de dentro: notas para uma etnografia urbana. Revista Brasileira de Ciências Sociais, 17(49), Junho/2002.

PERLONGHER, N. Territórios marginais. In: J.N. GREEN \& R. TRINDADE (Orgs.). O homossexualismo em São Paulo e outros escritos. São Paulo: Editora da UNESP, 2005.

RICOEUR, P. Interpretação e ideologias. Rio de Janeiro: Francisco Alves, 1977.

ROCHA, E.C. Estranhos encontros: aproximação etnográfica do táxi, sistema de transporte individual de passageiros. Monografia (Bacharelado em Antropologia). Brasília: Universidade Nacional de Brasília, 2004.

ROTENBERG, L. et al. Gênero e trabalho noturno: sono, cotidiano e vivências de quem troca a noite pelo dia. Cadernos de Saúde Pública, 17(3): 639-49, 2001.

SOARES, P. de M.A. \& SILVEIRA, F.L.A. Cidade em movimento: os taxistas como guardiões da memória em Belém do Pará. Amazônia: ciência \& desenvolvimento, 4(7), Julho/Dezembro, 2008.

VELHO, G. Observando o familiar". In: E. de O. NUNES (Org.). A aventura sociológica: objetividade, paixão, improviso e método na pesquisa social. Rio de Janeiro: Zahar, 1978.

VELOSO, T.M.G.; OLIVEIRA FILHO, P. de; MEDEIROS, C.S. de \& ARAUJO, A. dos S. A identidade em discursos de taxistas. Psicologia \& Sociedade, 21(1): 118-27, 2009.

VIEIRA, M.C. Hipertensão arterial e características ocupacionais em motoristas de táxi no Município do Rio de Janeiro. Dissertação apresentada com vistas à obtenção do título de Mestre em Ciências na área de Saúde Pública, 2009. 